\title{
Oral Submucous Fibrosis: the Soft Tissue Marble of Asia
}

\author{
Karthik D Yadav ${ }^{1 *}$ and PaiAnuradha² \\ ${ }^{1}$ Post Graduate student, Department of oral medicine and radiology, The oxford dental college and research center, India \\ ${ }^{2}$ HOD \& Professor, Department of oral medicine and radiology, The oxford dental college and research center, India
}

Received: December 20, 2017; Published: January 04, 2018

*Corresponding author: Karthik D Yadav, Post Graduate student, Department of oral medicine and radiology, The oxford dental college and research center, $10^{\text {th }}$ Milestone, Bommanahalli, Bangalore-560102, India; Tel: 919902824646, Email: karthikyadavd@gmail.com

\section{Introduction}

Oral squamous cell carcinoma is the sixth most common malignant neoplasm worldwide. Each year it accounts for more than 300,000 cases worldwide. The 5-year survival rate for OSCC has remained at approximately 50\% for the past several decades [1]. The impact of oral cancer is such that the disease and its treatment bring a heavy financial burden to both the social resources and the patient's family with psychological stress affecting the quality of life [2]. It develops through a multistep process of genetic, epigenetic and metabolic changes resulting from exposure to carcinogens, with initially the presence of a precursor/pre-cancer such as oral leukoplakia, oral erythroplakia oral submucous fibrosis. The most frequently reported etiological agents being tobacco, alcohol, chewing of betel quid containing areca nut [3]. The global incidence of oral submucous fibrosis is estimated at 2.5 million individuals. It is one of the most predominant potentially malignant conditions in South Asia with a high rate of prevalence in India, but is now also being acknowledged in Europe and North America [4-6]. The prevalence in Indian populations is $5 \%$ for women and $2 \%$ for men, which is reflected by the fact that the habit is more common among women in some geographic areas [7].

\section{Aetiopathogenesis}

Oral submucous fibrosis (OSMF) is a chronic inflammatory disease of the oral soft tissues with progressive juxta-epithelial fibrosis resulting in increasing difficulty in chewing, swallowing, speaking and mouth opening, often associated with burning sensation inside oral cavity that is aggravated on exposure to spicy food [8]. The habit of chewing betel nut (Areca catechu) is considered to be the main etiological agent, with others factors being genetic predisposition, infections and viral agents, carcinogens, nutritional and immunologic factors [8]. The role of chilliin the pathogenesis of OSMF remains controversial and is postulated as an hypersensitivity reaction to capsaicin due to allergen induced eosinophilia [6]. The mixture of areca nut and tobacco has led to a sharp increase in the frequency of OSMF [5]. A relationship has been observed between the areca quid consumption and development of OSMF.

Areca nut (Figure 1) contains alkaloids notably arecoline and guavacoline, with a wide range of parasympatheticomimetic effects, which modulate matrix metalloproteinases, lysyl oxidases and collagenases, which affect the collagen metabolism leading to fibrosis [7]. Concomitantly, a decrease in the water-retaining proteoglycans will occur which favors an increase in type I collagen production and the flavonoids catechin and tannin in the betel nut stabilizes the collagen fibers and makes them resistant to degradation by collagenase [6]. Genetically, polymorphism of the gene coding for tumor necrosis factor $\alpha$ (TNF- $\alpha$ ) leads to stimulation of fibroblasts and aberrations of other cytokines which include transforming growth factor $\beta$ and interferon- $\gamma$, lead to increased production and decreased degradation of collagen. Concomitant to tobacco chewing, smoking and consumption of alcohol increases the risk of oropharyngeal malignancies. $7 \%$ to $13 \%$ lesions of OSMF can transform into oral cancer, especially squamous-cell carcinoma over a period of 10 years [6-8].

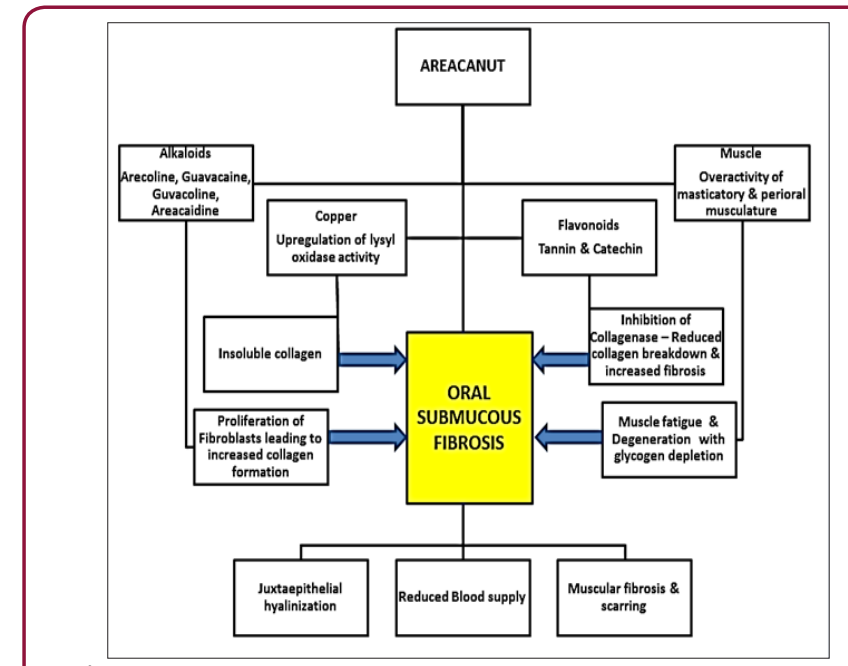

Figure 1.

\section{Clinical Features}

The buccal mucosa and retromolar area are the primary sites affected, followed by soft palate, palatal fauces, uvula, tongue and labial mucosa [6]. It occurs in the age group of 12-62 years with the mean age being 40 years. A definite female predilection, with the male: female ratio being 3:2 [6]. A difficulty in opening mouth 
accompanied with burning sensation is usually the reason for the patient's initial visit. On examination, blanching of the oral mucosa is noted which imparts a marble-like appearance, attributed to inflammation, trailed by hypovascularity and fibrosis that may be associated with small vesicles and mucosal erosions [8]. As the disease progresses, there may be stiffness of the tongue, blanched and leathery floor of the mouth, fibrotic, depigmentation of gingiva, Table 1: Pindborg has classified OSMF into 3 stages. rubbery soft palate with decreased mobility and blanched and atrophic tonsils, and shrunken bud like uvula with impairment of activities such as eating, whistling, blowing, sucking [6]. Other symptoms are increased salivation, change of gustatory sensation, hearing loss due to stenosis of the Eustachian tubes, dryness of the mouth, nasal tonality to the voice anddysphagia to solids. Pindborg has classified OSMF into 3 stages as shown in Table 1.

\begin{tabular}{|c|c|c|}
\hline \multicolumn{3}{|c|}{ Pindborg's Clinical Staging [9] } \\
\hline Stage 1: Early OSMF & Stage 2: Moderate OSMF & Stage 3: Severe OSMF \\
\hline & 1. Moderate to severe blanching & 1. Burning sensation very severe \\
\hline $\begin{array}{l}\text { 1. Mild blanching } \\
\text { 2. No restriction in mouth opening }\end{array}$ & $\begin{array}{l}\text { 2. Mouth opening reduced by } 33 \% \text {, tongue } \\
\text { protrusion reduced by } 33 \% \text { and reduced } \\
\text { flexibility }\end{array}$ & $\begin{array}{l}\text { 2. More than } 66 \% \text { reduction in the mouth } \\
\text { opening, cheek flexibility and tongue protrusion. } \\
\text { In much tongue may appear fixed }\end{array}$ \\
\hline $\begin{array}{l}\text { 3. No restriction in tongue protrusion up to } \\
\text { mesioincisalangle of upper central incisor when }\end{array}$ & $\begin{array}{l}\text { 3. Burning sensation even in the absence of } \\
\text { stimuli }\end{array}$ & 3. Ulcers over the buccal mucosa \\
\hline maximally extended with mouth wide open. & 4. Presence of palpable bands & 4. Thick palpable bands \\
\hline $\begin{array}{l}\text { 4. Burning sensation only on taking spicy food or } \\
\text { hot liquids. }\end{array}$ & $\begin{array}{l}\text { 5.Lymphadenopathy eitherunilateral or bilateral } \\
\text { 6. Demonstrable anemia on hematological } \\
\text { examination. }\end{array}$ & $\begin{array}{l}\text { 5. Bilateral lymphadenopathy, definite } \\
\text { nutritional compromise Can be established in B } \\
\text { complex (angular cheilitis) and iron deficiency } \\
\text { group. }\end{array}$ \\
\hline
\end{tabular}

\section{Diagnosis \& Investigations}

Diagnosis of the disease is mainly by clinical findings and can be confirmed by incisional biopsy. Other investigations include hematological, serological, immunological and biochemical factors which may reflect findings such as a raised ESR, slight eosinophilia, microcytosis and hyperchromic indicative of anemia. The differential diagnosis includes anemia and scleroderma which can be distinguished by other cutaneous, systemic and characteristic radiographic and laboratory findings [6].

\section{Management}

Management of OSMF includes use of hyaluronidase and corticosteroids or a combination of both. Other treatment modalities include antioxidants, Immunomodulators, Physiotherapy, Intereferon $-\gamma$, Hyper Baric Oxygen (HBO) therapy, Curcumin, Oxitard, Aloevera, Surgery $[6,8,10]$. Even though it is easy to diagnose but the irreversible condition reflects the failure of the present treatment modalities. The lack of knowledge and the delay in seeking treatment leads to the progression of the disease. Hence, more focus should be emphasized in detecting newer treatment modalities which is the need of the hour and the future.

\section{References}

1. S Gokul (2010) Oxidant-antioxidant status in oral squamous cell carcinoma patients. Oral Diseases 16(1): 29-33.

2. Han (2010) BMC Public Health 10:196

3. Gurkan Yardimci, ZekayiKutlubay, Burhan Engin, YalcinTuzun (2014) Precancerous lesions of oral mucosa. World J Clin Cases 2(12): 866-872.

4. Kumar S, Mohan C, Pagrani M, Srivastava A (2014) Oral submucous fibrosis - revisited. Annals of Dental Specialty 2(2): 43:46.

5. Wollina U, Verma SB, Ali FM, Patil K (2015) Oral submucous fibrosis: an update. Clinical, Cosmetic and Investigational Dermatology 8: 193-204.

6. Ongole RK, Praveen BN (2014) Textbook of Oral Medicine and Oral Diagnosis and Oral Radiology, 2nd ed. Elsevier Inc: 283-289.

7. Burket L, Greenberg M, Glick M, Ship J (2015) Burket's oral medicine. Hamilton, Ont. BC Decker 84: 98-117.

8. Jena AJ, Das SR (2016) A Review of Treatment Modalities in Oral Submucous Fibrosis. Int. J. Pharm. Sci. Rev. Res 36(2): 128-130.

9. Patil S, Maheshwari S (2014) Proposed new grading of Oral Submucous Fibrosis based on cheek flexibility. J Clin Exp Dent 6(3): 255-258.

10. M Ashwini Kumar (2015) Hyperbaric Oxygen Therapy in the Treatment of Oral Submucous Fibrosis. Journal of Clinical and Diagnostic Research 9(5): ZE01-ZE04.

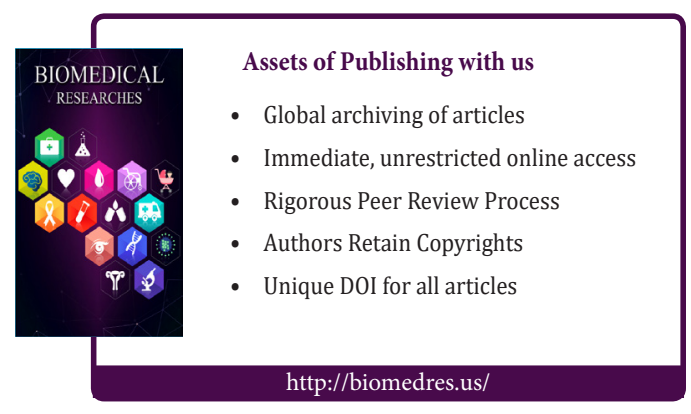

